\title{
Small dose spinal bupivacaine for Cesarean deliv- ery does not reduce hypotension but accelerates motor recovery
}

\author{
[Une faible dose de bupivacaïne intrathécale lors de l'accouchement par \\ césarienne ne réduit pas l'hypotension, mais accélère la récupération motrice]
}

Gregory L. Bryson MD FRCPC MSc, ${ }^{*}$ Robert MacNeil MD FRCPC, ${ }^{*}$ Leo M. Jeyaraj MBBS FRCA, $\dagger$

Ola P. Rosaeg MB BCh FRCPC

Background: Maternal hypotension occurs in $60-94 \%$ of Cesarean deliveries with 10-15 mg spinal bupivacaine. Reduced doses of bupivacaine may decrease the incidence of hypotension, nausea, and vasopressor use. The primary objective of this study was to compare $4.5 \mathrm{mg}$ and $12 \mathrm{mg}$ doses of intrathecal bupivacaine on maternal hemodynamics. The secondary objective was to determine if anticipated reductions in side effects were reflected in increased patient satisfaction.

Methods: Following Research Ethics Board approval and informed consent 52 term parturients undergoing elective Cesarean delivery were randomly assigned to isobaric bupivacaine $4.5 \mathrm{mg}$ or hyperbaric bupivacaine $12 \mathrm{mg}$ for spinal anesthesia. All patients received fentanyl $50 \mu \mathrm{g}$ and morphine $200 \mu \mathrm{g}$ intrathecally. Intravenous fluid and vasopressor administration were standardized. Maternal hemodynamics, and sensorimotor levels were recorded at regular intervals. Side effects and patient satisfaction were documented.

Results: Median cepahalad sensory block was C8 in both groups (NS) but the intensity of motor block was significantly less $(P<0.00 \mathrm{I})$ and of shorter duration $(P<0.00 \mathrm{I})$ with bupivacaine $4.5 \mathrm{mg}$. The proportion of patients requiring ephedrine (>70\%) and the quantities of ephedrine used were similar in both groups (NS). Use of supplemental analgesia, side effects, and measures of patient satisfaction were comparable in both groups.

Discussion: Intrathecal bupivacaine 4.5 and $12 \mathrm{mg}$ yielded similar sensory block and side effects during Cesarean delivery. Patients receiving $4.5 \mathrm{mg}$ did, however, experience significantly less motor blockade of shorter duration.

CAN J ANESTH $2007 / 54: 7 /$ pp 531-537
Contexte : L'hypotension maternelle se rencontre dans 60-94\% des accouchements par césarienne avec 10-15 mg de bupivacaïne intrathécale. Des doses réduites de bupivacaïne pourraient réduire l'incidence d'hypotension et de nausées, ainsi que l'utilisation de vasopresseurs. L'objectif premier de cette étude était de comparer l'effet de doses intrathécales de bupivacaïne de $4,5 \mathrm{mg}$ et $12 \mathrm{mg}$ respectivement sur l'hémodynamie maternelle. Le deuxième objectif était de déterminer si les réductions anticipées d'effets secondaires se reflétaient par une satisfaction accrue des patientes.

Méthode: Le Comité d'éthique de la recherche ayant donné son accord, cinquante-deux parturientes à terme devant subir un accouchement non urgent par césarienne ont été randomisées en deux groupes pour la rachianesthésie: bupivacaïne isobare 4,5 $\mathrm{mg}$ ou bupivacaïne hyperbare $12 \mathrm{mg}$. Toutes les patientes ont reçu du fentanyl $50 \mu \mathrm{g}$ et de la morphine $200 \mu \mathrm{g}$ en intrathécal. L'administration de liquide intraveineux et de vasopresseurs a été standardisée. L'hémodynamie maternelle ainsi que les niveaux sensori-moteurs ont été enregistrés à intervalles réguliers. Les effets secondaires et la satisfaction des patientes ont été documentés.

Résultats : Le bloc sensitif moyen en direction de la tête était situé à C8 dans les deux groupes (NS), mais l'intensité du bloc moteur était significativement plus faible $(P<0,00 I)$ et d'une durée moindre $(P<$ $0,00 \mathrm{I}$ ) avec la bupivacaïne 4,5 mg. La proportion de patientes nécessitant de l'éphédrine (> $70 \%$ ) et les quantités d'éphédrine administrées étaient similaires dans les deux groupes (NS). L'utilisation d'analgésie supplémentaire, les effets secondaires et la satisfaction des patientes étaient comparables dans les deux groupes.

Discussion: Dans le cas d'accouchements par césarienne, les doses de 4,5 mg et $12 \mathrm{mg}$ de bupivacaïne intrathécale produisent un bloc sensitif et des effets secondaires similaires. Toutefois, les patientes ayant reçu $4,5 \mathrm{mg}$ ont ressenti un bloc moteur plus faible et plus court, et cette différence était significative.

From the Department of Anesthesiology, ${ }^{*}$ The Ottawa Hospital, Ottawa, Ontario, Canada; the Department of Anaesthesia, $\dagger$ James Cook University Hospital, Middlesbrough, United Kingdom; and the Department of Anaesthetics, $\ddagger$ National Maternity Hospital, Dublin, Ireland. Address correspondence to: Dr. Gregory L. Bryson, Department of Anesthesiology, Box 249C, The Ottawa Hospital - Civic Campus, 1053 Carling Avenue, Ottawa, Ontario KIY 4E9, Canada. E-mail: glbryson@ohri.ca

This work was supported by the Departments of Anesthesia at the University of Ottawa and the Ottawa Hospital - Civic Campus.

An abstract of this work was presented at the 2006 Annual Meeting of the Canadian Anesthesiologists' Society June 17 - 20, Toronto,

Ontario, Canada.

Accepted for publication January 11, 2007.

Revision accepted April 6, 2007.

CAN J ANESTH 54: 7 www.cja-jca.org July, 2007 


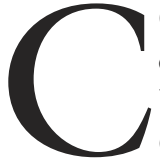

ONTEMPORARY anesthesia texts advocate the use of $12 \mathrm{mg}$ doses of hyperbaric bupivacaine for subarachnoid block for Cesarean delivery. ${ }^{1,2}$ Regrettably maternal hypotension occurs in 60-94\% of such anesthetics. ${ }^{3-5}$ Fluid preloading ${ }^{6}$ and the prophylactic use of ephedrine $^{4}$ do not consistently prevent maternal hypotension. Maternal hypotension frequently results in nausea and vomiting, which is distressing to the parturient lying supine on the operating table. The extensive motor block may result in severe claustrophobia and panic in susceptible parturients, sometimes requiring induction of general anesthesia. ${ }^{7}$ Dense motor blockade may last two to three hours and delay discharge from the postanesthesia care unit (PACU).

Factors traditionally assumed to be of greatest importance in determining the spread of local anesthetics in subarachnoid block include the baricity of local anesthetic solution, the dose of anesthetic chosen, the volume of injectate, and patient position following injection. ${ }^{8}$ Previous research has explored the influence of baricity and dose in the context of combined spinal-epidural anesthesia for Cesarean delivery. Sarvela et al. ${ }^{9}$ demonstrated that $9 \mathrm{mg}$ doses of hyperbaric and isobaric bupivacaine provided similar anesthesia and hemodynamics during Cesarean delivery but $>50 \%$ of patients in both groups required vasopressor support. In contrast, Vercauteren et al. ${ }^{10}$ demonstrated that a 6.6-mg dose of hyperbaric bupivacaine provided superior anesthesia and less hypotension than a similar dose of isobaric bupivacaine. To further complicate the issue, Ben-David et al. ${ }^{3}$ found that when using isobaric bupivacaine reducing the dose from 10 to $5 \mathrm{mg}$ decreased the incidence of hypotension, nausea, and the quantity of vasopressor used however, the interpretation of these finding is obscured by the selective use of intrathecal opioids in the low dose group.

The goal of this study was to maximize differences between traditional and low dose techniques by comparing of hyperbaric bupivacaine $12 \mathrm{mg}$ to isobaric bupivacaine $4.5 \mathrm{mg}$ in the context of a consistent regimen of intrathecal opioids. The doses and solutions were chosen to reflect those readily available to Canadian anesthesiologists. The primary objective of this study was to compare maternal vasopressor use during Cesarean delivery in patients receiving spinal bupivacaine $12 \mathrm{mg}$ and $4.5 \mathrm{mg}$. The secondary objective was to determine if anticipated reductions in hypotension, nausea, and motor blockade were reflected in increased patient satisfaction.

\section{Methods}

Following approval of the Ottawa Hospital Research Ethics Board parturients undergoing elective Cesarean delivery of singleton pregnancy at greater than 36 weeks gestation via a lower segment transverse incision were approached for informed written consent. Eligible patients were between 20 and $40 \mathrm{yr}$ of age and of ASA physical status I-II. Patients with the following characteristics were excluded: known hypersensitivity to any of the study medications; active labour; urgent or emergent deliveries; pre-eclampsia; pregnancy-induced hypertension; cardiac, renal, neurologic or other organ-system disease; $<152 \mathrm{~cm}$ or $>$ $174 \mathrm{~cm}$ in height; body weight $>100 \mathrm{~kg}$.

A randomization schedule allocating patients to the two study groups in random-permuted blocks of four was created using a computer-generated random numbers table. Allocation to 4.5 and $12 \mathrm{mg}$ groups was concealed using sequentially numbered, opaque envelopes. The randomization sequence remained concealed on a secure, password protected computer until all recruitment was complete. Patients were randomized on the day of delivery. Following randomization an investigator not involved with intraoperative care or measurement opened the envelope and prepared the study syringes. Patients in the small dose group received isobaric bupivacaine $4.5 \mathrm{mg}$ (0.9 $\mathrm{mL}$ of $0.5 \%$ bupivacaine) while those in the large dose group received hyperbaric bupivacaine $12 \mathrm{mg}$ (1.6 mL of $0.75 \%$ bupivacaine in dextrose). Patients in both groups received fentanyl $50 \mu \mathrm{g}(1 \mathrm{~mL})$ and morphine $200 \mu \mathrm{g}(0.4 \mathrm{~mL})$. All drugs for intrathecal injection were diluted with saline $0.9 \%$ to a final volume of 3 $\mathrm{mL}$. The syringes were placed on a sterile spinal anesthesia tray in the operating room before the arrival of the patient, anesthesiologist, other study personnel, or operating room staff. The tray was covered with a sterile drape to prevent contamination.

Patients received no premedication other than ranitidine $150 \mathrm{mg}$ po with a sip of water two hours before surgery. Demographic data (height, weight, parity, indication for surgery) were recorded. Patients received $500 \mathrm{~mL}$ of lactated Ringers' solution before intrathecal injection. Lumbar puncture was performed at the $\mathrm{L} 2-3$ interspace in the sitting position using a 25-G pencil-point spinal needle. Investigators were instructed to inject study medications over three seconds with the orifice of the needle in the cephalad direction. Following spinal injection the parturient was immediately placed in the supine position with left uterine displacement.

Automated, non-invasive blood pressure measurements were taken before injection of study medication, 
every minute for 15 min after injection, then every three minutes until the end of surgery. Ephedrine, in 5-10 mg iv boluses, was given when systolic blood pressure was $<95 \mathrm{mmHg}$ or when a $<25 \%$ decrease was measured compared with baseline (pre-spinal) value. These systolic blood pressure limits define the term hypotension for the purpose of this study. The total amount of ephedrine $(\mathrm{mg})$ used intraoperatively and total volume of lactated Ringer's solution infused were recorded.

The sensory and motor block progression was assessed with a blunt pin-prick and Bromage score respectively. Sensory motor block was assessed 5, 10, $30,60,90$ min after intrathecal injection, then every 30 min until resolution of the block. Motor block was assessed using the Bromage scale (0-3) and assessments were withheld during surgery. The definitions of this scale are: 0 , able to straight leg raise (SLR) and flex both feet and knees; 1, unable to SLR, able to flex knees and feet; 2 , unable to SLR or flex knees, able to flex feet; and 3, unable to move legs or feet.

Apgar scores, neonatal weight, and acid-base data from umbilical artery and vein were recorded. All patients received ondansetron $4 \mathrm{mg}$, dexamethasone $8 \mathrm{mg}$, and oxytocin at a rate of $3 \mathrm{U} \cdot \mathrm{hr}^{-1}$ after delivery. Patients complaining of discomfort during delivery received fentanyl $1.5 \mu \mathrm{g} \cdot \mathrm{kg}^{-1}$ (repeated once) then ketamine $0.2 \mathrm{mg} \cdot \mathrm{kg}^{-1} i v$. The incidence and timing of nausea, vomiting or discomfort were recorded.

Satisfaction with intraoperative anesthesia for Cesarean delivery was recorded on arrival in the PACU using a visual analogue scale (VASS) with "very dissatisfied" at $0 \mathrm{~cm}$ and "very satisfied" at 10 $\mathrm{cm}$. Those patients having had a previous Cesarean delivery were asked if they preferred their present or their previous anesthetic technique. Surgeons were asked to grade operating conditions as "very good," "good," or "poor."

On postoperative day one, two, and three patients were asked to assess the quality of their recovery using the quality of recovery (QoR) score. ${ }^{11}$ The QoR poses nine questions about quality of recovery and scores each response 0,1 , or 2. Possible results of the QoR range from 0 to 18 with higher scores representing better recovery. At the same intervals patients completed the visual analogue scale (VASR) with "poor recovery" at $0 \mathrm{~cm}$ and "excellent recovery" at $10 \mathrm{~cm}$.

Frequency of hypotension, nausea, vomiting, intraoperative discomfort, and preference for present technique among those undergoing repeat Cesarean delivery were assessed using the Chi-square statistic. Peak sensory dermatomal levels and Bromage scores were compared with the Wilcoxon rank sum test. The
TABLE I Demographic data

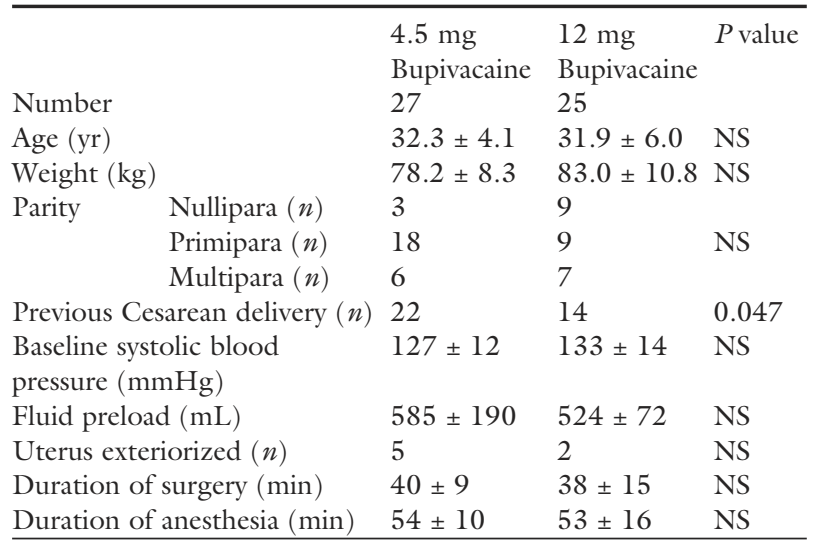

Results expressed as mean \pm SD when applicable. NS $=$ not statistically significant.

VASS, VASR and QoR scores were compared at individual time points with unpaired $t$ tests. Hemodynamic variables were compared using repeated measures analysis of variance (ANOVA). Statistically significant differences were assumed if $P<0.05$.

Sample size calculation was based on the results of a previous trial comparing high and low dose spinal anesthesia in Cesarean delivery. ${ }^{3}$ All calculations assumed a two-tailed alpha error of $5 \%$ and $80 \%$ power. A trial of only eight patients per group was required to confirm the reduction in the risk of hypotension reported by Ben-David (94\% in $10 \mathrm{mg}$ group vs $31 \%$ in the $5 \mathrm{mg}$ group). ${ }^{3}$ The risk of hypotension reported in the high dose group far exceeded our clinical experience and the baseline risk of hypotension reported in a systematic review of Cesarean anesthesia. ${ }^{4}$ Using the control rate of hypotension reported in the systematic review $(69 \%)$ a trial of 26 patients per group was required to confirm the rate of hypotension reported in BenDavid's low dose group (31\%).

\section{Results}

A total of 55 women were recruited. Two women were withdrawn after randomization when their surgery was postponed and a third was excluded for hypertension. The remaining 52 women completed the study protocol. The demographic characteristics of those completing the study are shown in Table I.

Cord $\mathrm{pH}$ at the time of delivery was $7.23 \pm 0.08$ and $7.26 \pm 0.08$ in the 4.5 and $12 \mathrm{mg}$ groups, respectively (NS). No infant had a cord $\mathrm{pH}$ of less than 7.00 at delivery. Apgar scores at one minute were $8.5 \pm 1.2$ 


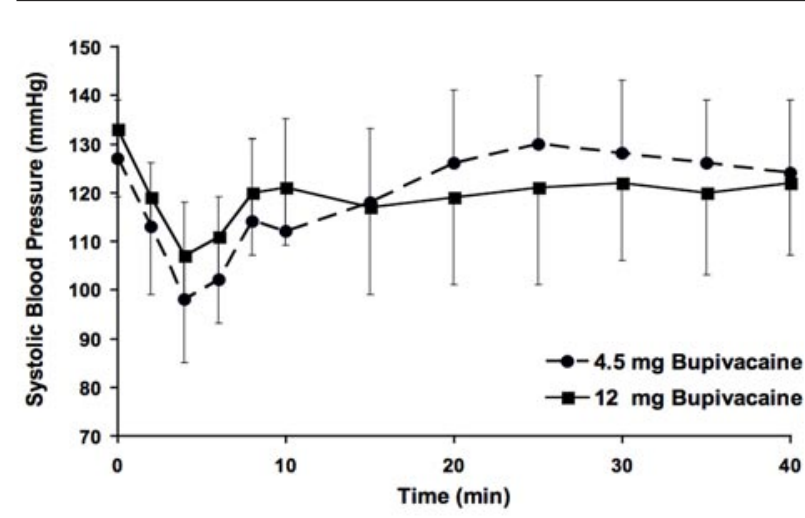

FIGURE Systolic blood pressure versus time following spinal anesthesia. Data presented are means and SD. Systolic blood pressure decreased significantly with time ( $P$ $<0.001)$ using repeated measures analysis of variance, but there was no significant difference between groups $(P=$ $0.390)$.

and $8.3 \pm 1.6$ in the 4.5 and $12 \mathrm{mg}$ groups, respectively (NS). Similarly, Apgar scores at five minutes were $9.1 \pm 0.3$ and $9.0 \pm 0.0$ in the 4.5 and $12 \mathrm{mg}$ groups (NS). Two neonates, one in each group, with a one minute Apgar less than 6 scored 9 at five minutes. No child had an Apgar of less than 9 at five minutes and none required resuscitation.

There was no difference in any of hemodynamic variables between dose groups (ANOVA: NS). Systolic arterial pressure is depicted graphically in the Figure. Hypotension requiring treatment was present in 20 of 27 patients in the bupivacaine $4.5 \mathrm{mg}$ group and 19 of 25 patients in the bupivacaine $12 \mathrm{mg}$ group (NS). Quantities of ephedrine $(12.8 \pm 12.5 \mathrm{mg}$ vs $11.8 \pm$ $12.1 \mathrm{mg}, \mathrm{NS}$ ) and total intravenous fluids (1573 \pm $285 \mathrm{~mL}$ vs $1678 \pm 521 \mathrm{~mL}$, NS) administered were similar in the 4.5 and $12 \mathrm{mg}$ dose groups, respectively.

Characteristics of the motor and sensory blocks observed are summarized in Table II. All patients in both groups had sensory blocks above the sixth thoracic dermatome within five minutes of induction. Use of supplemental analgesia in both groups was not significantly different (five of 27 in the $4.5 \mathrm{mg}$ group $v s$ one of 25 in the $12 \mathrm{mg}$ group dose, NS). One patient in the low dose group required a single dose of ketamine $10 \mathrm{mg}$ following fentanyl $150 \mu \mathrm{g}$ $i v$ in two divided doses to resolve intraoperative discomfort. All other complaints of inadequate analgesia were resolved with fentanyl $<100 \mu \mathrm{g} i \mathrm{v}$. No patient
TABLE II Characteristics of motor and sensory blocks

\begin{tabular}{|c|c|c|c|}
\hline & $4.5 \mathrm{mg}$ & $12 \mathrm{mg}$ & $P$ value \\
\hline $\begin{array}{l}\text { Maximum cephalad } \\
\text { sensory level }\end{array}$ & $\begin{array}{l}\text { Bupivacaine } \\
\text { C8 }(\mathrm{C} 6, \mathrm{~T} 2)\end{array}$ & $\begin{array}{l}\text { Bupivacaine } \\
\mathrm{C} 8(\mathrm{C} 6, \mathrm{~T} 1)\end{array}$ & NS \\
\hline $\begin{array}{l}\text { Time to maximum } \\
\text { cepahalad sensory } \\
\text { level (min) }\end{array}$ & $12.6 \pm 9.4$ & $19.2 \pm 17.4$ & NS \\
\hline $\begin{array}{l}\text { Time for two segment } \\
\text { regression of sensory } \\
\text { level }(\mathrm{min})\end{array}$ & $46.3 \pm 23.9$ & $58.4 \pm 26.7$ & NS \\
\hline $\begin{array}{l}\text { Maximum Bromage } \\
\text { score }(0-3)\end{array}$ & $0(0,1)$ & $3(3,3)$ & $<0.001$ \\
\hline $\begin{array}{l}\text { Time to maximum } \\
\text { Bromage score ( } \mathrm{min})\end{array}$ & $5.4 \pm 1.3$ & $17.4 \pm 21.8$ & 0.006 \\
\hline $\begin{array}{l}\text { Time to recovery to } \\
\text { Bromage score }=1(\mathrm{~min})\end{array}$ & $32.0 \pm 33.2$ & $158.6 \pm 44.9$ & $<0.001$ \\
\hline
\end{tabular}

Ordinal data expressed as median (interquartile range).

Continuous data expressed as mean \pm SD. NS $=$ not statistically significant.

TABLE III Patient satisfaction and quality of recovery

\begin{tabular}{|c|c|c|c|}
\hline & $\begin{array}{l}4.5 \mathrm{mg} \\
\text { Bupivacaine }\end{array}$ & $\begin{array}{l}12 \mathrm{mg} \\
\text { Bupivacaine }\end{array}$ & $P$ value \\
\hline $\begin{array}{l}\text { Intraoperative satisfaction } \\
\text { VAS }(0-10)\end{array}$ & $9.0 \pm 1.2$ & $9.0 \pm 1.3$ & NS \\
\hline \multicolumn{4}{|l|}{ Postoperative recovery } \\
\hline \multicolumn{4}{|l|}{$\operatorname{VASR}(0-10)$} \\
\hline Postoperative day 1 & $8.2 \pm 1.5$ & $7.8 \pm 1.3$ & NS \\
\hline Postoperative day 2 & $8.3 \pm 1.5$ & $7.9 \pm 1.7$ & NS \\
\hline Postoperative day 3 & $8.6 \pm 1.9$ & $7.9 \pm 1.5$ & NS \\
\hline \multicolumn{4}{|l|}{$\begin{array}{l}\text { Quality of recovery } \\
\text { score }(0-18)\end{array}$} \\
\hline Postoperative day 1 & $15.1 \pm 2.0$ & $14.8 \pm 2.6$ & NS \\
\hline Postoperative day 2 & $16.0 \pm 1.4$ & $16.0 \pm 2.7$ & NS \\
\hline Postoperative day 3 & $16.5 \pm 2.6$ & $16.1 \pm 2.5$ & NS \\
\hline $\begin{array}{l}\text { Previous Cesarean } \\
\text { delivery }(n)\end{array}$ & 22 & 14 & \\
\hline $\begin{array}{l}\text { Preferred current } \\
\text { technique }\end{array}$ & $13(59 \%)$ & $11(79 \%)$ & NS \\
\hline No preference & $7(32 \%)$ & $3(21 \%)$ & \\
\hline $\begin{array}{l}\text { Preferred previous } \\
\text { technique }\end{array}$ & $2(9 \%)$ & $0(0 \%)$ & \\
\hline
\end{tabular}

required conversion to general anesthesia. The depth of motor block and the time required for resolution of the motor block were significantly less in the $4.5 \mathrm{mg}$ group (Table II). The less intense and shorter motor block observed in the $4.5 \mathrm{mg}$ group permitted 26 of 27 patients to transfer themselves to the stretcher at the end of surgery; in contrast, only one of 25 patients in the $12 \mathrm{mg}$ group could transfer unassisted $(P<0.001)$. Surgeons described operating conditions 
as very good in 24 of 27 cases in the $4.5 \mathrm{mg}$ group and 24 of 25 in the $12 \mathrm{mg}$ group (NS). No surgeon graded operating conditions as poor.

Side effects were common in both groups. Despite antiemetic prophylaxis, nausea and/or vomiting occurred in nine of 27 patients in the $4.5 \mathrm{mg}$ group compared with ten of 25 patients receiving $12 \mathrm{mg}$ (NS). Similarly, pruritus was noted in 24 of 27 and 20 of 25 patients in the $4.5 \mathrm{mg}$ and $12 \mathrm{mg}$ groups, respectively (NS).

Patient satisfaction and QoR scores are summarized in Table III. Satisfaction with intraoperative anesthesia was high in both groups. Patient assessment of recovery by VASR and QoR scores was similarly high in both 4.5 and $12 \mathrm{mg}$ dose groups on postoperative days one, two and three. Correlations between VASR and QoR scores at similar times were statistically significant $(P<0.001$ at each assessment $)$ suggesting convergent validity between these measures of recovery. Among women who had previously had a Cesarean delivery only two preferred their previous anesthetic to that received in the present study.

\section{Discussion}

The primary results of this study suggest that decreasing the bupivacaine dose from $12 \mathrm{mg}$ to $4.5 \mathrm{mg}$ does not lead to reductions in hypotension and vasopressor use during Cesarean section. The $4.5 \mathrm{mg}$ dose, in combination with fentanyl and morphine, provided intraoperative analgesia, operating conditions, and side effect profile comparable to a $12 \mathrm{mg}$ dose. Low dose spinal anesthesia resulted in a motor block that was significantly less dense and of shorter duration, but did not influence patient satisfaction or quality of recovery.

Contrary to the results of the present study, BenDavid et al. ${ }^{3}$ demonstrated a threefold decrease in the incidence of hypotension and a nearly tenfold reduction in the amounts of ephedrine required in those patients receiving lower dose spinal anesthetics. Both studies employed similar fluid preloading strategies, definitions of hypotension and indications for vasopressor use. The only significant difference in the trials was noted in the median height of spinal block noted in the low dose groups. Patients in the $4.5 \mathrm{mg}$ group in the present study were noted to have blocks several dermatomes higher than those in either group of the Ben-David study. The broader spread of sensory anesthesia and sympathetic blockade might account for the minimal influence of dose on hemodynamic outcomes noted presently.

Factors influencing distribution of sensory and block during spinal anesthesia include baricity, rate of injection and volume of injection of the solutions employed. The baricity of the low dose solutions used in the present study ${ }^{12}$ was less than that of the cerebrospinal fluid of term parturients ${ }^{13}$ and would be comparable to those used in previous research. ${ }^{3}$ Horlocker et al. ${ }^{14}$ noted that an injection rate of 0.5 $\mathrm{mL} \cdot \mathrm{sec}^{-1}$ (equivalent to six seconds for the present study) yielded blocks approximately four dermatomes higher than when a similar dose was injected at 0.02 $\mathrm{mL} \cdot \mathrm{sec}^{-1}$ (equivalent to $150 \mathrm{sec}$ ). Similarly, the findings from an in vitro model of hypobaric spinal anesthesia demonstrate that injection rates ranging from 0.1 to $0.6 \mathrm{~mL} \cdot \mathrm{sec}^{-1}$ resulted in a wider distribution of drug ten minutes following the more rapid injection. These findings have not been replicated in other studies $^{15,16}$ but suggest that the relatively fast injection (1 $\mathrm{mL} \cdot \mathrm{sec}^{-1}$ ) employed in our study, compared with the $0.2 \mathrm{~mL} \cdot \mathrm{sec}^{-1}$ rate of injection used by Ben-David et $a .^{3}$ may have contributed to the rapid onset of block. Finally the influence of volume of injectate has been evaluated in a clinical trial comparing 2,5 , and $10 \mathrm{~mL}$ injections of a similar milligram dose of bupivacaine. Cephalad spread was greater in those receiving $10 \mathrm{~mL}$ but subjects given $2 \mathrm{~mL}$ and $5 \mathrm{~mL}$ behaved similarly. ${ }^{17}$ In this context, the volume of the solution used in the present study $(3 \mathrm{~mL})$ was not significantly different from the previous trial $(2 \mathrm{~mL}){ }^{3}$ The extensive cepahalad spread of anesthesia in both high and low dose groups described in our study may have obscured correlation between lower doses of bupivacaine and decreased maternal hypotension noted in previous research. These findings may be attributable to the faster rate of injection and slightly larger volume of injectate employed.

Patient and surgeon satisfaction with $4.5 \mathrm{mg}$ bupivacaine anesthesia was comparable to that noted with $12 \mathrm{mg}$ doses. Supplementation with parenteral opioid occurred in fewer than $20 \%$ of subjects and no patient required general anesthesia. These results conflict to some degree with Carvalho et al.' ${ }^{18}$ finding that 7.25 $\mathrm{mg}$ is the dose required to provide effective operative analgesia in $50 \%$ of subjects while $13 \mathrm{mg}$ is required to for effective analgesia in $95 \%$ of subjects. Onset times, cephalad extension of block, and hemodynamic endpoints were not clinically different in the present study and in Carvalho et al.'s patients, but anesthesia was successful at much lower doses in the present study. The divergence of outcomes may be explained by the present use of much a larger dose of intrathecal fentanyl.

Intrathecal fentanyl doses ranging from 2.5-60 $\mu \mathrm{g}$ were reported in a systematic review of intrathecal opioids for Cesarean delivery. ${ }^{19}$ The findings of this 
review suggest that intrathecal fentanyl in doses less than $35 \mu \mathrm{g}$ was associated with a $50 \%$ relative reduction in pruritus (34 vs 68\%) with comparable rates of nausea and vomiting when compared to doses 40-60 $\mu \mathrm{g}$. It is important to note that requests for supplemental analgesia were significantly reduced only in those patients receiving $40 \mu \mathrm{g}$ doses or greater. As our study explored doses of bupivacaine well below those reported in the literature we chose a dose of fentanyl $(50 \mu \mathrm{g})$ most likely to provide adequate analgesia.

Lower doses of fentanyl might have reduced the relatively high incidence of pruritus (85\%) and nausea (37\%) reported here. The concomitant use of intrathecal morphine for postoperative analgesia may, however, be responsible for some of the side effects noted. Systematic review ${ }^{19}$ identified pruritus resulted in over $50 \%$ of subjects receiving intrathecal morphine $100 \mu \mathrm{g}$ or more and nausea in $35 \%$ of those receiving the dose described in the present study. The QoR scores reported six hours postoperatively were similar to those noted following minor surgery ${ }^{11}$ suggesting opioid-related side effects did not significantly impair recovery.

Readers may question whether a low dose bupivacaine would work in their practice. We placed no limitations on our surgeon's practice in this study and made no attempt to alter the pace of their work. The uterus was exteriorized in approximately one fifth of subjects and "skin-to-skin" times of up to one hour in duration were recorded in those patients allocated to the $4.5 \mathrm{mg}$ group. A trend toward increased use of supplemental analgesia was noted in the low dose group. Post-hoc power analysis suggest that our study had only $38 \%$ power to confirm this trend and that a threefold increase in sample size would be required to document this finding with $80 \%$ power. It is important to note that among patients who had previously undergone Cesarean delivery a majority preferred the technique employed in this study.

In summary, the results of this study suggest that 4.5 and $12 \mathrm{mg}$ doses of bupivacaine administered with of fentanyl $50 \mu \mathrm{g}$ and morphine $200 \mu \mathrm{g}$ intrathecally provide similar anesthesia for Cesarean delivery. The lower dose was associated with neither a reduced incidence of hypotension nor a decrease in vasopressor use, most likely because of the rapid extension of the sensory block to the lower cervical dermatomes in both dose groups. Marked reduction in depth and duration of motor block were apparent in the lower dose group but did not influence patient satisfaction or quality of recovery. Future research is required to determine the dose of intrathecal fentanyl required to provide an adequate compromise between intraoperative analgesia and side effects.

\section{References}

1 Kuczkowski KM, Reisner LS. Anesthesia for cesarean section. In: Chestnutt DH (Ed.). Obstetric Anesthesia: Principles and Practice. Philadelphia: Elsevier Mosby; 2004: 421-46.

2 Santos AC, Braveman FR, Finster M. Obstetric anesthesia. In: Barash PG, Cullen BF, Stoelting RK (Eds). Clinical Anesthesia. Philadelphia: Lippincott Williams \& Wilkins; 2006: 1152-80.

3 Ben David B, Miller G, Gavriel R, Gurevitch A. Lowdose bupivacaine-fentanyl spinal anesthesia for cesarean delivery. Reg Anesth Pain Med 2000; 25: 235-9.

4 Lee A, Ngan Kee WD, Gin T. Prophylactic ephedrine prevents hypotension during spinal anesthesia for Cesarean delivery but does not improve neonatal outcome: a quantitative systematic review. Can J Anesth 2002; 49: 588-99.

5 Siddik-Sayyid SM, Aouad MT, Jalbout MI, Zalaket MI, Berzina CE, Baraka AS. Intrathecal versus intravenous fentanyl for supplementation of subarachnoid block during cesarean delivery. Anesth Analg 2002; 95: 20913.

6 Jackson R, Reid JA, Thorburn J. Volume preloading is not essential to prevent spinal-induced hypotension at caesarean section. Br J Anaesth 1995; 75: 262-5.

7 Rosaeg OP, Yarnell RW, Lindsay MP. The obstetrical anaesthesia assessment clinic: a review of six years experience. Can J Anaesth 1993; 40: 346-56.

8 Bridenbaugh PO, Greene NM, Brull SJ. Spinal (subarachnoid) neural blockade. In: Cousins MJ, Bridenbaugh PO (Eds). Neural Blockade in Clinical Anesthesia and Management of Pain. Philadelphia: Lippincott-Raven Publishers; 1998.

9 Sarvela PJ, Halonen PM, Korttila KT. Comparison of $9 \mathrm{mg}$ of intrathecal plain and hyperbaric bupivacaine both with fentanyl for cesarean delivery. Anesth Analg 1999; 89: 1257-62.

10 Vercauteren MP, Coppejans HC, Hoffmann VL, Saldien $V$, Adriaensen HA. Small-dose hyperbaric versus plain bupivacaine during spinal anesthesia for cesarean section. Anesth Analg 1998; 86: 989-93.

11 Myles PS, Hunt JO, Nightingale CE, et al. Development and psychometric testing of a quality of recovery score after general anesthesia and surgery in adults. Anesth Analg 1999; 88: 83-90.

12 Richardson MG, Wissler RN, Richardson MG, Wissler $R N$. Densities of dextrose-free intrathecal local anesthetics, opioids, and combinations measured at 37 degrees C. Anesth Analg 1997; 84: 95-9.

13 Richardson $M G$, Wissler RN. Density of lumbar cerebrospinal fluid in pregnant and nonpregnant humans. Anesthesiology 1996; 85: 326-30.

14 Horlocker TT, Wedel DJ, Wilson PR. Effect of injection 
rate on sensory level and duration of hypobaric bupivacaine spinal anesthesia for total hip arthroplasty. Anesth Analg 1994; 79: 773-7.

15 Anderson L, Walker J, Brydon C, Serpell MG. Rate of injection through Whitacre needles affects distribution of spinal anaesthesia. Br J Anaesth 2001; 86: 245-8.

16 Van Gessel EF, Praplan J, Fuchs T, Forster A, Gamulin $Z$. Influence of injection speed on the subarachnoid distribution of isobaric bupivacaine $0.5 \%$. Anesth Analg 1993; 77: 483-7.

17 Malinovsky JM, Renand G, Le Corre P, et al. Intrathecal bupivacaine in humans: influence of volume and baricity of solutions. Anesthesiology 1999; 91: 1260-6.

18 Carvalho B, Durbin M, Drover DR, Cohen SE, Ginosar $\Upsilon$, Riley ET. The ED50 and ED95 of intrathecal isobaric bupivacaine with opioids for cesarean delivery. Anesthesiology 2005; 103: 606-12.

19 Dabl JB, Jeppesen IS, Jorgensen H, Wetterslev J, Moiniche $S$. Intraoperative and postoperative analgesic efficacy and adverse effects of intrathecal opioids in patients undergoing cesarean section with spinal anesthesia: a qualitative and quantitative systematic review of randomized controlled trials. Anesthesiology 1999; 91 : 1919-27. 